UDC 316.422 .42

LBC 60.55

\title{
THE PANDEMIC SOCIAL SERVICES MARKET: NEW PRACTICES AND TECHNOLOGIES ${ }^{1}$
}

\author{
Yana I. Sitnikova \\ Volgograd State University, Volgograd, Russian Federation; \\ ANO "SOCIUM", Volgograd, Russian Federation \\ Natalia A. Nikolenko \\ Volgograd State University, Volgograd, Russian Federation
}

\begin{abstract}
This article analyzes the processes of development of the social service market, which is part of the social protection system. Through a comparative analysis of the Soviet and Russian models of social services, the authors conclude that the modern system, while partially retaining some characteristics of the Soviet system, is transforming and acquiring new specific features. Based on the generalization of the results of the authors' comprehensive sociological research using quantitative and qualitative methods (questionnaire survey, in-depth interviews, content analysis), the innovative practices of working with consumers (recipients) of social services, which social efficiency in the conditions of the COVID-19 pandemic was noted by respondents, used by NCOs operating in the social services market. Despite the complexity of objective circumstances faced by organizations, regional NCOs still managed to maintain the quality of social services provided in both online and offline formats at a level that meets the needs of recipients. The prospects for the development of SO NPOs are connected not only with the creation and implementation of innovative technologies and practices, but also depend on strengthening the personnel composition of employees through the development and subsequent implementation of proposals for protecting their health and improving professional competencies by creating conditions for training, advanced training and mastering new specialties. The article notes the important role of regional media in covering the activities of NGOs in the difficult period of the spread of coronavirus infection and the establishment of a forced regime of social isolation. An analysis of video materials broadcast on official channels of Volgograd television is given, which contributed to strengthening the status of NGOs as competitive providers of quality social services. It is predicted that the experience gained during the "pandemic" period will be used by NGOs in their day-to-day activities in the future.
\end{abstract}

Key words: socially oriented non-profit organizations, pre-retirees, regional social service market, everyday practices of NGOs, innovative social technologies, coronavirus pandemic, positive image of NGOs.

Citation. Sitnikova Ya.I., Nikolenko N.A. The Pandemic Social Services Market: New Practices and Technologies. Logos et Praxis, 2021, vol. 20, no. 2, pp. 110-123. (in Russian). DOI: https://doi.org/10.15688/ lp.jvolsu.2021.2.13

УДК 316.422 .42

ББК 60.55

\section{РЫНОК СОЦИАЛЬНОГО ОБСЛУЖИВАНИЯ НАСЕЛЕНИЯ В УСЛОВИЯХ ПАНДЕМИИ: НОВЫЕ ПРАКТИКИ И ТЕХНОЛОГИИ ${ }^{1}$}

\author{
Яна Игоревна Ситникова
}

Волгоградский государственный университет, г. Волгоград, Российская Федерация; $\mathrm{AHO} \mathrm{COH} \mathrm{«СОЦИУМ»,} \mathrm{г.} \mathrm{Волгоград,} \mathrm{Российская} \mathrm{Федерация}$

\section{Наталия Александровна Николенко}

Волгоградский государственный университет, г. Волгоград, Российская Федерация 
Аннотация. В статье анализируются процессы развития рынка социального обслуживания населения, являющегося частью системы социальной защиты. Посредством сравнительного анализа советской и российской моделей социального обслуживания населения, авторы статьи приходят к заключению, что современная система, частично сохраняя некоторые характеристики советской, преобразуется и приобретает новые специфические черты. На основе обобщения результатов проведенного авторами комплексного социологического исследования с применением количественных и качественных методов (анкетного опроса, глубинных интервью, контент-анализа) были зафиксированы используемые СО НКО, действующими на рынке социального обслуживания населения, инновационные практики работы с потребителями (получателями) социальных услуг, социальная эффективность которых в условиях пандемии COVID-19 была отмечена респондентами. Несмотря на сложность объективных обстоятельств, с которыми столкнулись организации, региональным СО НКО все же удалось сохранить качество социальных услуг, предоставляемых как в онлайн, так и в офлайн-форматах на уровне, удовлетворяющем потребности получателей. Перспективы развития СО НКО связаны не только с созданием и внедрением инновационных технологий и практик, но и зависят от усиления кадрового состава сотрудников посредством разработки и последующего внедрения предложений по охране их здоровья и повышению профессиональных компетенций путем создания условий для обучения, повышения квалификации и освоения новых специальностей. Отмечается весомая роль региональных СМИ в освещении деятельности СО НКО в сложный период распространения коронавирусной инфекции и установления вынужденного режима социальной изоляции. Приводится анализ видеоматериалов, транслируемых на официальных каналах волгоградского телевидения, которые способствовали усилению статусных позиций СО НКО, как конкурентоспособных поставщиков качественных социальных услуг. Делается прогноз, что полученный в «пандемийный» период опыт работы будет использован СО НКО и в дальнейшем в их повседневной деятельности.

Ключевые слова: социально ориентированные некоммерческие организации, предпенсионеры, региональный рынок социального обслуживания населения, повседневные практики СО НКО, инновационные социальные технологии, пандемия коронавируса, позитивный имидж СО НКО.

Цитирование. Ситникова Я. И., Николенко Н. А. Рынок социального обслуживания населения в условиях пандемии: новые практики и технологии // Logos et Praxis. - 2021. - T. 20, № 2. - C. 110-123. - DOI: https:// doi.org/10.15688/lp.jvolsu.2021.2.13

\section{Введение}

В условиях пандемии, вызванной новой коронавирусной инфекцией - COVID-19, CO НКО столкнулись с новыми вызовами, направленными на обеспечение непрерывного процесса предоставления социальных услуг гражданам, нуждающимся в социальной поддержке и помощи, особенно тем, которые в связи с принятием ограничительных мер на государственном уровне, связанных с периодом «самоизоляции», не могут в полной мере реализовать свой социальный, реабилитационный и профессиональный потенциал. В связи с этим актуальным становится изучение, с одной стороны, новых практик и технологий СО НКО, изменение их стратегий поведения в связи с пандемией. А с другой, глубинный анализ советской системы социального обслуживания населения в проекции на те практики, которые сейчас используются в повседневной деятельности СО НКО.

\section{Система социального обслуживания в СССР: утрата преемственности или новые векторы развития?}

Система социального обслуживания в СССР характеризовалась разветвленной сетью государственных организаций различных форм облуживания (стационарной, полустационарной, на дому), предоставляющих социальную помощь населению. Основу ее создания и функционирования составляла идеология этатизма - огосударствление социальной сферы, что выражалось в четкой распределительной системе (70-95 \% средств направлялось из государственного бюджета) и жестком контроле со стороны государства. Общественные организации, как и в настоящее время участвовали в предоставлении социальных услуг населению. Однако допуск этих организаций к обслуживанию населения строго контролировался. Если деятельность каких-либо общественных организаций не соответствовала установленным требованиям 
и не отражала интересы системы социального обслуживания советского времени, то они ограничивались в реализации социальных задач государства [Тевлина 2008, 400; Олимских 2007].

Анализ научной литературы, посвященной вопросам социального обслуживания в советское время, не позволяет безоговорочно утверждать, что советская система социального обслуживания населения коренным образом отличалась от той, которая существует сегодня. Хотя подобные попытки при проведении сравнительного анализа советской и современной российской системы социального обслуживания населения предпринимаются. Например, ряд исследователей [Игольникова 2010; Лукьянова, Сигида 2009] отмечает, что в советское время система социального обслуживания граждан отличалась многообразием видов социальной помощи нетрудоспособным гражданам, всеобщностью охвата населения в предоставлении социальной помощи, унифицированностью социального обслуживания. Аккумулирование финансовых ресурсов в государственном бюджете и бездефицитность страховых средств сводили к минимуму степень социальных рисков и обеспечивали гарантированность получения бесплатной медицинской и социальной помощи. Отмечаются также имеющиеся, по мнению некоторых исследователей [Кибардина 2010; Трохирова, Зимина 2010; Кулькова 2020], недостатки советской системы социального обслуживания населения: кадровый дефицит, выражающийся в отсутствии подготовленных профильных специалистов, способных предоставлять различные виды социальных услуг (например, сиделок и др.); нарушение по тем или иным причинам декларируемого принципа «общедоступности» социальной поддержки, который на практике не всегда был реализован. Кроме того, сформировалась патерналистская система, выражающаяся в исключительной обязанности и ответственности государства за решение социальных проблем граждан. Все это способствовало снижению социальной активности граждан и сведению в узко ограниченные рамки формы социальной помощи. И, в конечном итоге, привело в последней четверти двадцатого века к разрушению системы социального обслуживания «изнутри» и «снаружи», социальному иждивенчеству и кадровому «голоданию».

В работах вышеотмеченных исследователей, безусловно, есть как «рациональные зерна», так и моменты, которые могут быть предметом дальнейшей научной дискуссии. Хотелось бы также подчеркнуть, что черты советской системы социального обслуживания населения проявляются и в настоящее время: сохраняются контроль со стороны государственных структур и распределительная система государственного бюджета; в приоритете и у общества, и у государства в основном остаются государственные организации, предоставляющие социальные услуги, в том числе и потому, что в отдаленных районах различных регионов они, как и прежде, сохраняют монопольные позиции. Вместе с тем необходимо отметить, что современный рынок социального обслуживания значительно расширился засчет включения в него новых «игроков» в лице СО НКО и немногочисленной части организаций иных форм собственности (ИП, ООО, ЗАО, АО), которые способны предоставлять конкурентоспособные инновационные социальные услуги.

С точки зрения экономической выгоды все же сохраняется непривлекательность данного рынка для большей части бизнес-структур и субъектов малого и среднего предпринимательства в связи с низкими тарифными ставками за предоставляемый перечень государственных социальных услуг и низкой платежеспособностью граждан, которые могли бы оплачивать дополнительные социальные услуги. Несмотря на это, по нашему мнению, будущее системы социальной защиты населения тесно связано с рынком социальных услуг, в котором наличие баланса между социально ориентированными НКО, государственными организациями и организациями иных форм собственности, работающих в сфере социального обслуживания, будет одним из основных ее показателей.

\section{Современные тенденции на региональных рынках социального обслуживания}

Анализируя современную систему социального обслуживания населения (в том числе рынка социальных услуг и социального об- 
служивания населения), ряд исследователей констатируют длящийся процесс ее формирования. Продолжаются научные дискуссии, касающиеся рассмотрения данной системы как социального института и противоречивости в оценках составляющих его элементов [Андрющенко 2012; Бухалова, Павлова, Литвинчук 2020; Петровская 2019; Григорьева, Сизова, Москвина 2019; Лазуренко, Серкина 2018; Васильцова, Невьянцева 2017; Палибина и др. 2017, Парфенова 2018].

Несмотря на это, по нашему мнению, четко прослеживаются определенные черты российской модели социального обслуживания населения. Например, государство (подчеркнем это еще раз) по-прежнему остается монополистом в сфере социального сервиса, однако определенная часть потребителей (получателей социальных услуг) лишена права выбора поставщика в связи с тем, что их распределением во многих регионах занимаются центры социальной защиты населения, то есть выбор поставщика социальных услуг в начальном звене их предоставления сохраняется за государством. Более того, продолжается стандартизация и унификация социальных услуг, которые находят отражение, к сожалению, иногда и в индивидуальных программах получателя социальных услуг, хотя у многих обратившихся за помощью граждан имеются свои особенности и жизненные потребности.

Что немаловажно, сохраняются экономические и административные барьеры для включения на рынок негосударственных организаций, о которых уже упоминалось выше: низкая ценовая политика, специфические условия выбора поставщиков социальных услуг и обращение к СО НКО только в том случае, если социальные услуги не могут предоставить государственные организации. Все это «делает» данный рынок в определенной степени непривлекательным для негосударственных организаций.

Нельзя не согласиться и с точкой зрения исследователей, которые считают, что для современного рынка социального обслуживания характерны: а) латентное сочиальное взаимодействие между государством и обществом, направленное на решение проблем только тех граждан, которые «попадают» под официально установленную государ- ством категорию нуждающихся в социальной помощи (и это несмотря на наметившееся разгосударствление данного рынка услуг); б) превалирование традиционных практик предоставления социальных услуг; в) коммерциализация засчет возможности предоставления дополнительных социальных услуг; г) многосубъектность, выражающаяся в расширении перечня организаций, предоставляющих социальные услуги; д) динамизм в законодательстве [Мигунова 2019]. Например, чтобы вступил в силу Федеральный закон № 442-Ф3 «О социальном обслуживании граждан в Российской Федерации» возникла необходимость в изменении регионами более 50 нормативных правовых региональных актов. В условиях пандемии коронавируса также были внесены изменения в положения об оказании социальных услуг, на основании которых стало возможным предоставлять социальные услуги в дистанционном формате [Парий-Сергеенко, 2018].

Следует также отметить слабую подготовленность базы для оценки рынка социальных услуг. Приходится констатировать, что детально изучаются только экономические показатели рынка, а социальные факторы, влияющие на его формирование, остаются «в тени» и, как правило, не учитываются. На наш взгляд, необходимо заострить внимание на сочетании социальных и экономических факторов, что позволит проводить комплексную оценку деятельности участников рынка. Кроме того, требуют более детального научного изучения и осмысления связанные с современным российским рынком социального обслуживания населения такие аспекты, как: а) явные и латентные социальные взаимодействия «игроков» на рынке, их стратегии и практики поведения; б) мотивы и предпочтения; в) ресурсы; г) механизмы, которые способствовали бы созданию позитивного имиджа рынка и делали бы его привлекательным для всех участников; д) система качества социального обслуживания населения (опыт ее внедрения и функционирования в различных организациях, разработка индикаторов оценки «социальной услуги» и оценка уровня качества предоставляемых социальных услуг); е) понимание руководителями СО НКО роли государственного и общественного контроля. 
Все указанные аспекты являются важными, и мы считаем, что их изучение имеет не только научную, но и практическую значимость.

Интересной, на наш взгляд, представляется точка зрения российских и зарубежных исследователей [Парфенова 2017, Парфенова, Петухова 2019; Кулькова 2020; Worth 2009; Саралиева, Петрова 2019; Палибина и др. 2017; Парий-Сергиенко 2018], которые предлагают рассматривать российский рынок социального обслуживания населения как сетевой, в котором государственные и негосударственные организации, именуемые «социальными сервисами» или «провайдерами» по предоставлению социальных услуг, действуют точно также как субъекты сетевых рынков других профилей. Более того в работах вышеприведенных авторов фиксируется появление новых тактик данных субъектов - «социальных сервисов» (в основном в лице государственных «игроков») в условиях складывающейся социальной реальности, характерными чертами которой является усиление конкуренции между «государственными социальными сервисами» (как основными крупными провайдерами социальной работы) и СО НКО. Активность «Государственных игроков», по мнению ученых, объясняется тем, что СО НКО демонстрируют более высокий потенциал по сравнению с государственными организациями: ассортимент предлагаемых социальных услуг шире, а готовность использовать инновации выше (в том числе, и в плане внедрения в повседневную практику новых форм и видов работы). Потенциал и возможности СО НКО вызывают даже некую обеспокоенность у определенной части представителей государственных организаций, действующих на рынке социального обслуживания населения. К примеру, анализ проведенных в 14 регионах страны интервью со специалистами ЦСОН/ КЦСОН выявил, что представители этих государственных организаций считают СО НКО своими прямыми конкурентами и не понимают, почему им предоставляется государственная поддержка, если под угрозу ставится существование «родных» и привычных для граждан центров социального обслуживания населения (ЦСОН/КЦСОН) [Кулькова 2020]. Однако недопонимание происходящих процессов не снижает накала конкурентной борьбы и заставляет государственные сервисы (государственные организации) использовать следующие тактики:

1. «Лавирование и убеждение»: получателям социальных услуг предоставляются дополнительные социальные услуги, которые не включены в индивидуальную программу получателя; допускается «разделение» полномочий в части их предоставления с СО НКО (часть услуг предоставляет государство на основании договора, а часть СО НКО). Появляются новые практики «бронирования» мест в стационарных отделениях социального обслуживания, пребывание пожилого человека в которых освобождает родственников от ухода за ними в домашних условиях; в качестве второго варианта рассматривается форма организации ухода, получившая название «Теплая совместная забота», реализуемая родственниками и представителями социальных служб.

2. «Здоровье, досуг и присмотр»: внедряются дополнительные платные социальные услуги, предоставляющие полный спектр социально-медицинских, педагогических, психологических, правовых и трудовых услуг (детские сады для пожилых граждан, дневные отделения в полустационарных организациях социального обслуживания, в которых получатель социальных услуг проводит полдня, санатории на дому, мобильные бригады и др.)

3. «Добровольчество и молодежь»: в рамках данных практик привлекаются партнеры и спонсоры для предоставления материальной помощи получателям социальных услуг; добровольческие организации, волонтеры, которые формируют заявки на уборку квартир и домов, организуют помощь на приусадебных территориях, а также посещают совместно с получателями социальных услуг театры, кафе, музеи и выставки.

Таким образом, в настоящее время в сфере социального обслуживания населения начинают проявляться черты, которые в советское время отсутствовали. В их ряду прежде всего следует отметить наличие конкуренции между государственными и негосударственными организациями (что особенно проявляется в городской среде), новое понимание клиентоориентированности, как принципа 
работы (что выражается в стремлении удовлетворить разнообразные и все возрастающие потребности граждан, в адресности и доступности предоставляемых услуг, во внедрении стационарозамещающих технологий, позволяющих сохранить «привычные» для получателя услуг условия пребывания).

\section{Пандемия: возрождение новых практик или уход назад?}

Благотворительной организацией - Фондом поддержки и развития филантропии «КАФ», в 2020 г. было проведено социологическое исследование, посвященное вопросам влияния новой коронавирусной инфекции COVID-19 деятельность CO НКО «Новая реальность. Как COVID-19 меняет работу российских НКО». Результаты исследования показали, что превалирующая часть опрошенных руководителей СО НКО (67 \%) считает, что в новых «пандемийных условиях» нарушилась социальная коммуникация: приходилось отказываться от рабочих поездок, личных встреч и т. д. Вторым немаловажным фактором, затрудняющим повседневную деятельность СО НКО, стала вынужденная необходимость перевода сотрудников на дистанционную (удаленную) работу ( 83 \%), что неблагоприятным образом сказалось на реализации грантовых проектов, засчет которых многие НКО существуют и которые выполнить в онлайн-режиме было весьма затруднительно (с подобными трудностями столкнулись $35 \%$ руководителей СО НКО от общего числа опрошенных). Около $25 \%$ опрошенных руководителей СО НКО отметили, что их работников не устраивали технические условия удаленной работы (у большинства сотрудников нет персональных компьютеров, средств для обеспечения обратной связи). В результате $7 \%$ из общего числа привлеченных к опросу СО НКО не смогли приспособиться к новым условиям работы и были вынуждены отстраниться от выполнения своих повседневных функциональных обязанностей. Кроме того, как отмечают представители СО НКО, существенно (на 60 \%) снизился уровень пожертвований от партнеров, благотворителей и меценатов.

Однако были и положительные моменты, на которые обращали внимание руководи- тели СО НКО. Например, достаточно большое количество респондентов $(53,4 \%)$ отметили, что к сотрудникам СО НКО стали относиться как к экспертам-профессионалам, которые, несмотря на имеющиеся сложности в условиях пандемии коронавируса и самоизоляции, все же могут оказывать социальную помощь. Больше половины опрошенных $(55,6$ \%) подчеркнули, что для них открылись новые возможности, связанные с постановкой стратегических задач дальнейшего развития СО НКО и разработкой новых направлений работы (таких как, онлайн-фандрайзинг и др.). Больше половины СО НКО (54,4 \%) планируют реализовать новые проекты, внедряют новые форматы предоставления социальных услуг и собираются в дальнейшем переводить часть работы в онлайн-режим [Ходорова, Максимова web].

Появление новых практик в деятельности СО НКО отмечается в ряде работ отечественных исследователей [Волкова 2020; Свищева, Конева, Серкина 2018; Лазуренко, Серкина 2018], в которых подчеркивается, что в условиях пандемии COVID-19 CO HKO стали предлагать новые практики и технологии, позволяющие адаптироваться к условиям социальной реальности как получателям социальных услуг, так и их сотрудникам (в том числе предпенсионного и пенсионного возраста, которых в этих организациях немало).

Для выявления новых практик и технологий, применяемых на рынке социального обслуживания населения в условиях пандемии, авторами данной статьи в апреле - мае 2020 г. в Волгоградской области было проведено качественное исследование методом глубинных интервью с руководителями СО НКО, а также сотрудниками указанных организаций и учебных центров на тему: «Повседневная деятельность СО НКО в условиях пандемии: новые практики и технологии». В исследовании приняли участие 33 руководителя СО НКО, 11 сотрудников - предпенсионеров СО НКО, 5 сотрудников учебных центров, занимающихся переобучением и повышением квалификации предпенсионеров. Критериями отбора являлись: опыт работы (не менее двух лет) в должности руководителя / сотрудника в системе социального обслуживания населения или учебного центра, предоставляющего услуги по 
повышению квалификации и переобучению граждан и принимавших непосредственное участие в повышении квалификации и переобучении граждан предпенсионного возраста в рамках государственной программы.

\section{По результатам исследования было выявлено, что в условиях пандемии:}

1. Востребованными формами государственной поддержки сотрудников, в том числе и предпенсионного возраста, являются: предоставление адресных субсидий всем СО НКО (а не только реализуемых в рамках грантовой поддержки, которую получают не все организации), направленных на страхование жизни и здоровья сотрудников данной возрастной категории, которые работали с гражданами во время пандемии; организация приемов и консультаций у наиболее востребованных медицинских специалистов; заключение коллективных договоров социального страхования.

«Необходимо развивать адресную поддержку сотрудников СО НКО, страховать их по здоровью, проводить медицинские осмотры, стимулировать различными мерами поддержки» (Ж., 60 л., президент СО НКО).

2. Существует необходимость использования сотрудниками СО НКО всех возрастов возможностей получения появившихся новых «онлайн-профессий», особенно популярных среди граждан старшего поколения: «SMM-менеджер», «Преподаватель онлайнкурсов», «Автор блога / Ютуб-канала», «Руководитель интернет-магазина», «Копирайтер», «Ретушер». Для овладения этими профессиями нужны: усидчивость, дисциплинированность, стремление к результату, а этими качествами обладают многие сотрудники СО НКО. Новые знания могут быть полезны и при выполнении функциональных обязанностей сотрудников СО НКО и станут своеобразной «подушкой безопасности» в случае потери работы.

«Я организовала свой видеоблог «с кулинарными рецептами от бабушек», я делюсь «вкусными рецептами» и секретами приготовления успешных блюд. Подписчики активно комментируют и ставят лайки. А внук говорит, что скоро я могу стать известным блогером-кулинаром. Я создала тему для общения пользователей и любой желающий может поделиться своим рецептом. Планирую за- пустить конкурс на самую оригинальную подачу блюда» (Ж., 56 л., социальный работник СО НКО).

3. Имеется необходимость предоставления «социальных ваучеров» на переобучение сотрудников предпенсионного возраста и направление их по данным ваучерам на курсы повышения компьютерной грамотности, приобретения навыков работы с умными «интернет-вещами» с последующей передачей своих знаний гражданам, получающим социальные услуги.

«Считаю, что нужно расширять направления работы с сотрудниками, проводить переобучение, так как сейчас необходимо работать в онлайн-формате, а без должного обучения это практически невозможно... Мне сложно...» (Ж., 65 л., директор СОНКО).

4. Существует потребность в большем освещении в рамках социальной рекламы преимуществ обучения и переобучения граждан предпенсионного и пенсионного возраста в связи с переходом общества в цифровую реальность.

«Потеря работы в предпенсионный период или выход на пенсию не всегда означает конец трудовой карьеры. Если вы хотите работать и зарабатывать, попробуйте делать это удаленно из дома. Не бойтесь, что раньше никогда этого не делали: ваши «офлайн»-навыки пригодятся для работы в интернете. Освоить нужные для онлайн-профессий навыки можно удаленно на онлайн-курсах» (Ж., 60 л., руководитель учебного центра «Познание».)

Необходимо проводить работу по ознакомлению сотрудников с возможностями реализации государственных программ переобучения предпенсионеров по востребованным направлениям деятельности: а) педагогика, кадровое дело и PR; б) туризм; в) строительство; г) охрана труда; д) библиотечное дело; е) менеджмент и управление; ж) транспорт, бухгалтерия; 3) экономика; и) государственные закупки; к) информационные технологии. Многие из этих направлений могут быть peaлизованы в работе СО НКО. Вот, например, что отметила одна из респонденток:

«Я прошла переобучение по направлению работы «Информационные технологии». И сейчас 
могу все заявки на обслуживание и на доставку продуктов питания заносить в компьютер» (Ж., 57 л., сиделка, помощник по уходу СО НКО).

5. СО НКО в ответ на вызовы социальной реальности стали активно внедрять инновационные технологии и практики.

Вот что отметил один из респондентов:

«Мы ввели новые дополнительные пакеты социальных услуг, оказываемые онлайн и офлайн (на дому), как для сотрудников, так и для наших клиентов. Например, для граждан старшего поколения и инвалидов предоставляются услуги визажа, парикмахерские услуги, обучение компьютерной грамотности, оказание помощи в трудоустройстве: регистрация на порталах, размещающих информацию об имеющихся вакансиях, консультирование по вопросам открытия собственного дела, помощь в написании резюме на дому» (М., 33 г., исполнительный директор СО НКО).

Введены в практику санитарно-эпидемиологические правила организации труда:

- внедрена в обязательном порядке бесплатная обработка моющими средствами поверхностей в жилых помещениях получателей социальных услуг;

- сотрудникам организаций предоставлены средства индивидуальной защиты (маски, перчатки, спреи).

6. СО НКО был расширен спектр дополнительных досуговых инновационных услуг в режиме онлайн. Появились виртуальные группы по интересам, объединившие пожилых людей (получателей социальных услуг):

«...унас введены виртуальные беседки для пожилых граждан: клубы любителей кино, поэзии; групповая онлайн-зарядка, йога, гимнастика, физкультура; онлайн курсы английского и немецкого языков и др.» (М., 42 г., директор СО НКО).

7. Предоставляется грантовая поддержка на оказание комплекса дистанционных социальных услуг молодым людям с инвалидностью.

«Мы получили грантовую поддержку на развитие системы оказания комплекса дистанционных социальных услуг подросткам и молодежи с ментальной инвалидностью в г. Волжский Волгоградской области. Обеспечена дистанционная работа специалистов удаленно, привлечен системный администратор, который поможет настроить оборудование и обеспе- чит работу связи вовремя онлайн занятий» (Ж., 66 л., исполнительный директор СО НКО).

8. Внедряются инкубаторы социальных услуг, службы сиделок, отражающие круглосуточное социальное обслуживание получателей социальных услуг, открываются горячие линии по доставке продуктов питания, лекарственных препаратов для граждан старшего поколения и инвалидов.

Активно развивается социальное предпринимательство, направленное на обеспечение реабилитационным оборудованием граждан, нуждающихся в помощи. Усилия сотрудников направлены на поддержание психологического и социального статуса получателей социальных услуг (граждан старшего поколения).

«Служба сиделок - одна из форм стационарозамещающих технологий социального обслуживания одиноко проживающих граждан. Направлена на предоставление условий продления пребывания человека в привычной «домашней» среде и повышение качества жизни получателя социальных услуг не обязательно тяжелобольного» (М., 33 г., исполнительный директор СО НКО).

9. Сотрудники СО НКО Волгоградской области, в отличие от своих коллег (сотрудников из других регионов) не признали, что в условиях новой социальной реальности коммуницировать на должном уровне стало сложнее. Кроме того, сроки реализации проектов, намеченные ранее в 2020 г., были перенесены в связи с распространением новой коронавирусной инфекции COVID-19 самими грантооператорами на другой период. Но это никак не отразилось на ухудшении их деятельности по предоставлению социальных услуг населению - основной задаче данных СО НКО.

10. Одной из проблем, с которой не готовы были столкнуться СО НКО Волгоградской области, была кадровая нехватка специалистов, возникшая в связи с заболеванием сотрудников, предоставляющих социальные услуги, что повлекло за собой увеличение нагрузки тех социальных работников, которые не заболели COVID-19 или уже на данный момент прошли лечение (на одного социального работника приходилось 8-10 получателей социальных услуг в различных удаленных друг от друга районах). 
Кроме того, нарушился штатный режим работы организаций. Это выразилось в нарушении сроков предоставления отчетности в контролирующие органы и в органы законодательной и исполнительной власти; в несвоевременном предоставлении информации о реализуемой деятельности организаций, в снижении качества ответов на запросы различных структур.

«Наша организация столкнулась с непредвиденными обстоятельствами непреодолимой силы, несмотря на предпринятые меры защиты сотрудников, стало невозможным остановить эпидемию. Мы столкнулись с тем, что сотрудников, которые бы могли предоставлять социальные услуги, значительно уменьшилось в связи с заболеванием. Встала необходимость пересмотра трудовой нагрузки. С административным персоналом было все также, что снизило работу в организации. На письма не успевали отвечать и т. д.» (Ж., 55 л., директор СО НКО).

11. В качестве позитивного момента представителями СО НКО было отмечено возросшее доверие со стороны общества к СО НКО. В период пандемии в них увидели профессионалов, которые могут оказать социальную помощь, являются более «гибкими» и более способными к адаптации к изменяющимся условиям.

«Я заметила, что к нам стали обращаться все больше из государственных организаций, других фондов для предоставления не только социальных слуг, но и проведения благотворительных социальных акций, мероприятий, способствующих борьбе с COVID-19» (M., 54 г., директор СО НКО).

12. В условиях пандемии социальные взаимодействия между самими СО НКО значительно улучшились: снизилась конкуренция, организации объединялись для решения проблем клиентов, все усилия были направлены на борьбу с коронавирусной инфекцией без снижения качества предоставления социальных услуг и обеспечение бесперебойной работы любыми способами.

«Я заметила, что в условиях пандемии мы, $\mathrm{HKO}$, все сплотились. Приведу пример, если организация не справлялась (не было, например, pe- сурсов для выполнения какой-то задачи), то данная НКО обращалось в другую организацию и перепоручала своего получателя социальных услуг ей. Цель была одна - помочь» (Ж., 44 г., директор СО НКО).

Интересной, на наш взгляд, является оценка уровня освещенности деятельности СО НКО в условиях пандемии на региональных телевизионных каналах, являющихся одним из основных и популярных средств распространения информации в обществе. Авторами данной статьи был проведен контентанализ видеороликов, посвященных деятельности СО НКО в условиях пандемии. В выборку были включены официально зарегистрированные телевизионные каналы на территории Волгоградской области (в качестве единиц анализа было взято количество видеороликов, посвященных полностью или частично деятельности СО НКО в условиях пандемии, которые были проанализированы в сравнении с представленными в 2019 г. на официальных региональных телевизионных каналах (ГТРК «Волгоград - ТРВ», Телеканал «МТВ - телевидение Волгограда», Телеканал «Волгоград-1», «Волгоградское деловое телевидение»).

По результатам проведенного анализа по сравнению с 2019 г. в 2020 г. на 19,05\% увеличилось количество транслируемых видеороликов, в которых активно освещалась деятельность СО НКО в условиях пандемии (соответственно годам их было 17 и 21). Изменились также содержательное наполнение и тематическая направленность деятельности СО НКО в СМИ. Выражается это в следующем: если в 2019 г. деятельность СО НКО освещалась с точки зрения их участия в конкурсах на предоставление грантовой поддержки (17.09.2019 «Волгоградские НКО проведут профилактическую работу с помощью областных грантов»; 22.01.2019 «В Волгоградской области стартовал конкурс по предоставлению субсидий некоммерческим организациям»; 06.08.2019 «Волгоградские НКО станут темой общественной экспертизы», «Волгоградские НКО: лидеры в получении грантов»; 15.10.2019 «Волгоградские НКО реализуют 143 проекта по президентским грантам») и применения новых сочиальных технологий (20.12.2019 «Волгоград- 
ские НКО презентовали передовые технологии в сфере долговременного ухода»; 09.07.2019 «1500 жителей Волгоградской области получают помощь социальных бригад»; 18.05.2019 «Национальный проект «Демография»: Волгоградские НКО включились в долговременный уход за пожилыми людьми»), то в 2020 г. основными тематическими линиями стали вопросы по организащии и оказанию помощи гражданам региона СО НКО в условиях пандемии (22.10.2020 «Как в Волгоградской области организована работа социальных НКО»; 03.12.2020 «Социальные НКО оказали волгоградцам 5 млн услуг с начала года»; 19.03.2020 «ОНФ объявил всеобщую НКО-мобилизацию для защиты населения от коронавируса»; 11.03.2021 «В Волгограде подвели итоги работы по поддержке старшего поколения в 2020 году», 08.04.2020 «В Волгограде обсудили перспективы участия НКО в оказании соцуслуг населению»; 07.12.2020 «В Волгограде при поддержке Фонда президентских грантов открылось антикафе «У друзей»); о мерах поддержки, предоставляемых СО НКО (09.06.2020 «540 волгоградских НКО внесены в Федеральный реестр для получения поддержки»; 11.06.2020 «Пострадавший от пандемии бизнес, НКО в Волгограде избавили от налогов»), о возможностях переобучения предпенсионеров (15.04.2020 «В Волгограде расширяют возможности для НКО по обучению предпенсионеров»), о популяризации деятельности НКО (16.03.2020 «Что такое НКО, как они зарабатывают и какие возможности у них есть?»; 22.10.2020 «Как в Волгоградской области организована работа социальных НКО»).

Проделанная региональными СМИ в этом направлении работа позволяет отметить их огромный вклад в популяризацию деятельности СО НКО (демонстрацию их практик, потенциала), направленной на помощь людям в сложных условиях эпидемии.

Следует также отметить, что авторами статьи в целях проверки гипотезы о возможном снижении качества предоставляемых социальных услуг в условиях пандемии был организован и проведен анкетный опрос в рамках социологического исследования: «Качество предоставляемых социальных услуг СО НКО в условиях распространения новой коронавирусной инфекции» (апрель 2020 г. - январь 2021 г.), в котором приняли участие 372 получателя социальных услуг, обслуживающихся СО НКО в период пандемии. Примечательно, что по мнению практически всех респондентов $(95,4$ \%), качество социальных услуг не изменилось, хотя предоставлялись они в онлайн формате. Привлечение СО НКО на рынок социальных услуг в условиях пандемии респондентами было оценено положительным образом в связи с тем, что данные организации являются мобильными, а также оперативно и качественно реагируют на запросы получателей социальных услуг (так считают $62,7 \%$ опрошенных).

Таким образом, гипотеза о возможном снижении качества предоставляемых социальных услуг в онлайн-формате не подтвердилась.

Более того, некоторые социальные услуги (доставка продуктов питания, лекарственных препаратов, сопровождение получателей социальных услуг сотрудником НКО в медицинские учреждения) в условиях пандемии коронавируса стали бесплатными, хотя ранее они вынуждены были их оплачивать (это отметили $63,7 \%$ респондентов).

По мнению большинства респондентов $(86,3 \%)$, стало уделяться более пристальное внимание к представителям старшего поколения со стороны не только СО НКО, но и социальных служб, добровольцев, соседей. Популярными формами поддержки граждан данной возрастной категории стали: приобретение лекарственных препаратов (93,3\%), вынос твердых бытовых отходов $(83,5 \%)$, доставка продуктов питания $(98,4 \%)$, оплата ЖКХ $(100 \%)$. В целом, качество и объем предоставляемых указанных офлайн социальных услуг, как отметили 98,3 \% респондентов, не снизился.

Одной из положительных практик стала возможность предоставления в качестве социальной услуги транспорта для организации проезда в медицинские учреждения и прививочные пункты, а также сдачи тестов на COVID-19 получателями социальных услуг (это отметили 93,3\% респондентов).

Обобщая все вышеизложенное, следует подчеркнуть: 
1. СО НКО в условиях современной реальности стремятся приспособиться к быстро изменяющимся условиям и предложить новые социальные услуги, которые в последующем могут быть внедрены в повседневную практику.

2. Накопленный опыт, скорее всего, будет использован СО НКО и после пандемии. К примеру, в связи со значительной экономией ресурсов СО НКО могут перевести в режим удаленной работы некоторых своих сотрудников-программистов и тех, кто занимается вопросами организации социального обслуживания граждан. Сохранятся также онлайн-мероприятия, направленные на реализацию досуговых практик граждан старшего поколения, которые проводились СО НКО в качестве их поддержки (клубы любителей кино, фитнеса и т. п.). В то же время ряд социальных услуг (проведение кружковых занятий для детей, психологическая диагностика и обследование личности ребенка и т. п.), которые в условиях пандемии были переведены в онлайн-режим, могут быть возвращены в обычный офлайн-формат.

3. Социальное взаимодействие социально ориентированных некоммерческих организаций вышло на новый уровень партнерства: во время пандемии, несмотря на конкуренцию между организациями и борьбу за клиентов, СО НКО обращались за помощью друг к другу с целью предоставить социальные услуги их получателю. Мы считаем, что данный тип социального партнерства имеет все основания укорениться в социальной практике СО НКО и даже стать предметом дальнейшего изучения.

В заключение хотелось бы отметить, что сложившаяся из-за пандемии коронавирусная ситуация стала своеобразной проверкой жизнеспособности российской системы социального обслуживания населения в целом, и СО НКО, задействованных в этой сфере, в частности. Региональные СО НКО, работающие на волгоградском рынке социального обслуживания населения, продемонстрировали свою конкурентоспособность, инновационный потенциал и заботу не только о получателях социальных услуг, но и о своих сотрудниках, чье настоящее и будущее, как показали результаты проведенных исследований, им небезразлично.

\section{ПРИМЕЧАНИЕ}

${ }^{1}$ Статья подготовлена при поддержке РФФИ в рамках научного проекта № 20-011-00519 «Вызовы и риски формирования нового гендерного порядка и социальный механизм управления им в России».

The article was prepared with the support of the Russian Federal Property Fund in the framework of the scientific project No. 20-011-00519 "Challenges and risks of the formation of a new gender order and the social mechanism of its management in Russia".

\section{СПИСОК ЛИТЕРАТУРЫ}

Андрющенко 2012 - Андрющенко О.Е. Формирование модели социальной защиты населения в условиях социальной модернизации России // Вестник Волгоградского государственного университета. Серия 7, Философия. Социология и социальные технологии. 2012. № 3 (18). C. $172-176$.

Бухалова, Павлова, Литвинчук 2020 - Бухалова Н.А., Павлова О.А., Литвинчук В.И. Рынок социальных услуг: проблемы и перспективы развития // Вестник НГИЭИ. 2020. № 3. С. 112-121.

Васильцова, Невьянцова 2017 - Васильцова Л.И., Невьянцева Н.Н. Рынок социальных услуг: векторы развития и социально-экономические последствия // Дискуссия. 2017. № 5. C. 68-73.

Волкова 2020 - Волкова О.А. НКО в условиях пандемии: развитие структур гражданского общества в контексте саморегуляции и государственного управления // Академия труда и социальных отношений. 2020. № 4. С. 5-17.

Григорьева, Сизова, Москвина 2019 - Григорьева И.А., Сизова И.Л., Москвина А.Ю. Социальное обслуживание пожилых: реализация Федерального закона № 442 и дальнейшие перспективы // Мониторинг общественного мнения: Экономические и социальные перемены. 2019. № 4. С. 153-172.

Игольникова 2010 - Игольникова В.А. Элементы социального государства в советской России 1917-1920 гг. // Социология власти. 2010. № 1. C. $166-173$.

Кибардина 2010 - Кибардина Л.Н. Особенности патерналистской модели российского социального государства // Омский научный вестник. 2010. № 4. С. 63-67.

Кулькова 2020 - Кулькова В.Ю.Некоммерческий сектор и государственная поддержка некоммерческих организаций сферы услуг в РФ в условиях кризиса 2020 года // Проблемы 
управления: теория и практика. 2020. № 80. C. 1-17.

Лазуренко, Серкина 2018 - Лазуренко Н.В., Серкина М.С. Проблема качества услуг в нестационарном учреждении социального обслуживания для пожилых людей Белгородской области // Logos et Praxis. 2018. № 2. С. 133-144. DOI: https://doi.org/10.15688/lp.jvolsu.2018.2.13.

Лукьянова, Сигида 2009-Лукьянова И.Е., Сигида Е.А. Из истории становления медико-социальной помощи в России // Сервис plus. 2009. № 2. C. 9-13.

Мигунова 2019 - Мигунова М.В. Основные черты и тенденции развития современной Российской системы социального обслуживания населения // Вестник Пермского национального исследовательского политехнического университета. Социально-экономические науки. 2019. № 3. C. 39-51.

Олимских 2007 - Олимских Н.Н. Социальная защита населения: понятие и содержание // Вестник Удмуртского университета. 2007. № 2. С. 1-8.

Палибина и др. 2017 - Палибина А.С., Панькова Е.Г., Соловьева Т.В., Бистяйкина Д.А. Некоммерческие организации в системе социального обслуживания населения // Дискуссия. 2017. № 10. С. 55-59.

Парий-Сергеенко 2018 - Парий-Сергеенко Е.П. Нормативные основы социального обслуживания граждан пожилого возраста // Право и современные государства. № 4. 2018. С. 67-72.

Парфенова 2017 - Парфенова O.A. Социальные сервисы для пожилых: формальные и неформальные правила и практики // Журнал исследований социальной политики. 2017. № 4. С. 573-586.

Парфенова 2018 - Парфенова О.А. Трансформация социального обслуживания пожилых в региональном контексте современной России // Журнал социологии и социальной антропологии. 2018. № 2. С. 165-186.

Парфенова, Петухова 2019 - Парфенова О.А., Петухова И.С. Конкуренция за заботу о пожилых: тактики социальных сервисов в новых условиях // Мониторинг общественного мнения: Экономические и социальные перемены. 2019. № 4. С. 173-186.

Петровская 2019 - Петровская Ю.А. Модернизация системы социального обслуживания в контексте инновационного развития Российской Федерации: механизмы и барьеры // Вестник Пермского университета. Философия. Психология. Социология. 2019. № 2. С. 230-240.

Саралиева, Петрова 2018 - Саралиева 3.Х., Петрова И.Э. Пожилые в российской негосударственной социальной работе // Журнал ис- следований социальной политики. 2018. № 1. С. $95-108$.

Свищева, Конева, Серкина 2018 - Свищева И.К., Конева Т.Н., Серкина М.С. Активизирующие технологии социального обслуживания как фактор улучшения социального самочувствия пожилых людей и инвалидов в Белгородской области // Вестник Майкопского государственного технологического университета. 2018. № 1. С. 103-108.

Тевлина 2008 - Тевлина В.В. Система социальной помощи населению в период формирования советского государства (1918-1930-е гг.) // Благотворительность в истории России: новые документы и исследования. СПб.: НесторИстория, 2008.

Трохирова, Зимина 2010 - Трохирова У.В., Зимина Е.В. Проблемы кадрового обеспечения системы социальной защиты и социального обслуживания населения и стратегические направления их решения (на примере г. Иркутска) // Baikal Research Journal. 2010. № 5. C. 63-69.

Ходорова, Максимова web - Ходорова Ю., Максимова О. Новая реальность. Как Covid-19 меняет работу российских НКО // https:// philanthropy.ru/analysis/2020/03/24/87056/.

Worth 2009 - Worth M. Nonprofit Management: Principles and Practice. Los Angeles; L.; New Delhi; Singapore; Washington: SAGE, 2009.

\section{REFERENCES}

Andryushchenko O.E., 2012. Formation of a Model of Social protection of the population in the Conditions of Social Modernization of Russia. Science Journal of Volgograd State University. Philosophy. Sociology and Social Technologies, no. 3, pp. 172-176.

Buhalova N.A., Pavlova O.A., Litvinchuk V.I., 2020. Social Services Market: Problems and Prospects of Development. Vestnik NGIEI, no. 3, pp. 112-121.

Volkova O.A., 2020. NGOs in the Context of a Pandemic: The Development of Civil Society Structures in the Context of Self-Regulation and Public Administration. Akademiya truda i social'nyh otnoshenij, no. 4, pp. 5-17.

Vasil'cova L.I., Nev'yancova N.N., 2017. Social Services Market: Development Vectors and Socio-Economic Consequences. Diskussiya, no. 5 , pp. 68-73.

Grigor'eva I. A., Sizova I.L., Moskvina A.Y., 2019. Social Services for the Elderly: Implementation of Federal Law No. 442 and Future Prospects. Monitoring obshchestvennogo mneniya: Ekonomicheskie $i$ social'nye peremeny, no. 4, pp. 153-172. 
Igol'nikova V.A., 2010. Elements of the Social State in Soviet Russia 1917-1920. Sociologiya vlasti, no. 1, pp. 166-173.

Kibardina L.N., 2010. Features of the Paternalistic Model of the Russian Social State. Omskij nauchnyj vestnik, no. 4, pp. 63-67.

Kul'kova V.Y., 2020. The Non-Profit Sector and State Support for Non-Profit Organizations in the Service Sector in the Russian Federation in the Context of the 2020 Crisis. Problemy upravleniya: teoriya i praktika, no.80, pp. 1-17.

Lazurenko N.V., Serkina M.S., 2018. The Problem of Quality of Services in the Non-Stationary Social Service Institution for the Elderly in Belgorod Region. Logos et Praxis, no. 2, pp. 133-144. DOI: https://doi.org/10.15688/lp.jvolsu.2018.2.13.

Luk'yanova I.E., Sigida E.A., 2009. From the History of the Formation of Medical and Social Care in Russia. Servis plus, no. 2, pp. 9-13.

Migunova M.V., 2019. The Main Features and Trends in the Development of the Modern Russian Social Service System. Vestnik Permskogo nacional'nogo issledovatel'skogo politekhnicheskogo universiteta, no. 3, pp. 39-51.

Olimskih N.N., 2007. Social Protection of the Population: Concept and Content. Vestnik Udmurtskogo universiteta, no. 2, pp. 1-8.

Palibina A.S., Pan'kova E.G., Solov'eva T.V., Bistyajkina D.A., 2017. Non-Profit Organizations in the Social Service System. Diskussiya, no. 10, pp. 55-59.

Parij-Sergeenko E.P., 2018. Regulatory Framework for Social Services for Elderly Citizens. Pravo $i$ sovremennye gosudarstva, no. 4, pp. 67-72.

Parfenova O.A., 2017. Social Services for the Elderly: Formal and Informal Rules and Practices. Zhurnal issledovanij social'noj politiki, no. 4, pp. 573-586.

Parfenova O.A., 2018 Transformation of Social Services for the Elderly in the Regional Context of Modern Russia. Zhurnal sociologii $i$ social'noj antropologii, no. 2, pp. 165-186.

Parfenova O.A., Petuhova I.S., 2019. Competition for the Care of the Elderly: Tactics of Social Services in the New Conditions. Monitoring obshchestvennogo mneniya: Ekonomicheskie I social'nye peremeny, no. 4, pp. 173-186.

Petrovskaya Y.A., 2019. Modernization of the Social Service System in the Context of Innovative Development of the Russian Federation: Mechanisms and Barriers. Vestnik Permskogo universiteta, no. 2, pp. 230-240.

Saralieva Z.H., Petrova I.E., 2018. The Elderly in Russian Non-Governmental Social Work. Zhurnal issledovanij social'noj politiki, no. 1, pp. 95-108.

Svishcheva I.K., Koneva T.N., Serkina M.S., 2018. Activating Technologies of Social Services as a Factor of Improving the Social Well-Being of the Elderly and Disabled in the Belgorod Region. Vestnik Majkopskogo gosudarstvennogo tekhnologicheskogo universiteta, no. 1, pp. 103-108.

Tevlina V.V., 2008. The System of Social Assistance to the Population During the Formation of the Soviet State (1918-1930). Charity in the History of Russia: New Documents and Research, SanktPeterburg, Nestor-Istoriya Publ.

Trohirova U.V., Zimina E.V., 2010. Problems of Personnel Support of the System of Social Protection and Social Services of the Population and Strategic Directions of Their Solution (On the Example of Irkutsk). Baikal Research Journal, no. 5, pp. 63-69.

Khodorova Y., Maksimova O., 2020. A New Reality. How Covid-19 is Changing the Work of Russian NGOs. URL: https://philanthropy.ru/analysis/ 2020/03/24/87056/.

Worth M., 2009. Nonprofit Management: Principles and Practice. Los Angeles, London, New Delhi, Singapore, Washington, SAGE Publ. 
Я.И. Ситникова, Н.А. Николенко. Рынок социального обслуживания населения в условиях пандемии

\section{Information About the Authors}

Yana I. Sitnikova, Candidate for a Degree, Department of Sociology and Social Technologies, Volgograd State University, Prosp. Universitetsky, 100, 400062 Volgograd, Russian Federation, jana3194@mail.ru; Deputy Director, ANO “Socium”, Zemlyachki St, 72, Bld.1, 400117 Volgograd, Russian Federation,nkosocium@mail.ru, https://orcid.org/0000-0003-4762-7620

Nataliya A. Nikolenko, Candidate of Sciences (Sociology), Associate Professor, Department of Sociology and Social Technologies, Volgograd State University, Prosp. Universitetsky, 100, 400062 Volgograd, Russian Federation, nikolenko@volsu.ru, https://orcid.org/0000-0002-8968-460X

\section{Информация об авторах}

Яна Игоревна Ситникова, соискатель кафедры социологии и социальных технологий, Волгоградский государственный университет, просп. Университетский, 100, 400062 г. Волгоград, Российская Федерация, jana3194@mail.ru; заместитель директора АНО СОН «СОЦИУМ», ул. им. Землячки, 72, пом. 1, 400117 г. Волгоград, Российская Федерация, nkosocium@mail.ru, https://orcid.org/0000-0003-4762-7620

Наталия Александровна Николенко, кандидат социологических наук, доцент кафедры социологии и социальных технологий, Волгоградский государственный университет, просп. Университетский, 100, 400062 г. Волгоград, Российская Федерация, nikolenkovolsu@mail.ru, https://orcid.org/0000-0002-8968-460X 